\title{
Mice with Blunted Hypoxic Ventilatory Response are Susceptible to Respiratory Disturbance during Hypoxia
}

\author{
Tetsuya Adachi, ${ }^{1}$ Hiromasa Ogawa, ${ }^{1,2}$ Shinichi Okabe, ${ }^{1}$ Tomomi Kitamuro, ${ }^{1}$ \\ Yoshiniro Kikuchi, ${ }^{1}$ Shigeki Shibahara, ${ }^{3}$ Kunio Shirato ${ }^{1}$ and Wataru Hida ${ }^{1,2}$ \\ ${ }^{I}$ Department of Cardiovascular and Respiratory Medicine, Tohoku University \\ School of Medicine, ${ }^{2}$ Health Administration Center, Tohoku University, \\ ${ }^{3}$ Department of Molecular Biology and Applied Physiology, Tohoku University \\ School of Medicine, Sendai, Japan
}

Adachi, T., Ogawa, H., Okabe, S., Kitamuro, T., Kikuchi, Y., Shibahara, S., Shirato, K. and Hida, W. Mice with Blunted Hypoxic Ventilatory Response are Susceptible to Respiratory Disturbance during Hypoxia. Tohoku J. Exp. Med., 2006, 209 (2), 125-134 - Hypoxia causes a life-threatening situation, and the ventilatory response to hypoxia plays an important role in preventing death. We have hypothesized that persons with a blunted hypoxic ventilatory response may have a weak defense response to hypoxic episodes and be susceptible to fatal respiratory disturbances. However, precise correlations between the hypoxic ventilatory response and respiratory disturbances are not well understood. In the present study we examined the hypoxic and hypercapnic ventilatory responses in nine inbred mouse strains (A/J, AKR/N, BALB/c, C3H/He, C57BL/6, DBA/2, $\mathrm{NZW}, \mathrm{SWR} / \mathrm{J}$, and 129Sv). Breathing frequency, tidal volume and minute ventilation of unanesthetized and unrestrained mice were assessed by whole body plethysmography. Age-matched mice were exposed for 3 min to $10 \% \mathrm{O}_{2}$ in $\mathrm{N}_{2}$ gas or $10 \% \mathrm{CO}_{2}$ in hyperoxic gas to determine the acute ventilatory response to chemical stimuli. Basal respiratory variables and hypoxic ventilatory responses differed among the strains, but the hypercapnic ventilatory response did not differ. The hypoxic ventilatory response was the highest in AKR/N mice and the lowest in SWR/J mice. These findings suggest that genetic factors may have influenced the hypoxic ventilatory response but not the hypercapnic ventilatory response. To examine the effects of severe hypoxic stress on the respiratory cycle, we exposed the strain with the highest or lowest hypoxic ventilatory response to $6 \% \mathrm{O}_{2}$ in $\mathrm{N}_{2}$ until the onset of apnea. The "appearance time of apnea", which is defined as the time from the hypoxic loading to the onset of apnea, was shorter in the SWR/J strain than in the $\mathrm{AKR} / \mathrm{N}$ strain. We suggest that a lower hypoxic ventilatory response may be a risk factor for apnea under hypoxia. —— blunted ventilatory reponse; hypoxic-induced apnea; genetics; respiration; animal (C) 2006 Tohoku University Medical Press

Received January 11, 2006; revision accepted for publication March 27, 2006.

Correspondence: Wataru Hida, M.D., Ph.D., Health Administration Center, Tohoku University, Kawauchi 41, Aoba-ku, Sendai 980-8576, Japan.

e-mail: hida@health.is.tohoku.ac.jp 
The immediate hypoxic ventilatory response of vertebrates occurs in response to a lower fractional $\mathrm{O}_{2}$ concentration, either in steps or progressively. Usually, a brief hypoxic exposure stimulates the peripheral chemoreceptors, resulting in a rapid increase in ventilation. This hypoxic ventilatory response may be important in some respiratory diseases that can trigger life-threatening episodes. Hunt et al. (1981) reported that infants with sudden infant death syndrome had lower hypoxic ventilatory responses than the control group. We found that persons with near fatal asthma showed lower hypoxic ventilatory responses than normal subjects and asthma patients without experience of near fatal asthmatic attack (Kikuchi et al. 1994). Furthermore, Hackett et al. (1988) reported that persons who experienced high altitude pulmonary edema showed lower hypoxic ventilatory responses than the control group. From these clinical studies, we hypothesized that persons with a blunted hypoxic ventilatory response may have a weak defense response to hypoxic episodes and be susceptible to fatal respiratory disturbances. However, to the best of our knowledge, there have been no reports showing that a blunted hypoxic ventilatory response is associated with respiratory disturbances, because it would be difficult to undertake this kind of investigation in a human study.

Tankersley et al. (1994) reported that there were differences in ventilatory behavior during exposure to hypoxia or hypercapnia among unanesthetized inbred mice, and suggested the presence of genetic influences on both responses. Therefore, it may be possible to identify mice strains with a blunted hypoxic ventilatory response by comparing the hypoxic ventilatory responses of inbred mice. Severe hypoxia could produce respiratory disturbance such as hypoxicinduced apnea (Guntheroth and Kawabori 1975). Thus it would be possible to examine the relationship between a blunted hypoxic ventilatory response and respiratory disturbance using mice.

In the present study we examined the ventilatory responses of 9 inbred male mouse strains that we could obtain, and identified two mouse strains with the highest and lowest ventilatory responses. Then, we studied the ventilatory responses in these two mouse strains during a prolonged exposure to $6 \%$ oxygen, showing that the mice with the lowest ventilatory response had shorter "appearance time of apnea" than the mice with the highest ventilatory response. We suggest that severe hypoxia might easily cause respiratory disturbances, such as apnea, in an animal with the blunted hypoxic ventilatory response.

\section{Materials ANd Methods}

Animals

Nine inbred male mice $(\mathrm{A} / \mathrm{J}, n=12 ; \mathrm{AKR} / \mathrm{N}, n=$ 13; BALB/c, $n=8 ; \mathrm{C} 3 \mathrm{H} / \mathrm{He}, n=11 ; \mathrm{C} 57 \mathrm{BL} / 6 n=10$; $\mathrm{DBA} / 2, n=13$; NZW, $n=8$; SWR $/ \mathrm{J}, n=14$; and 129Sv, $n=8)$ matched for age ( $8-12$ weeks) and weight (24 $26 \mathrm{~g}$ ), were supplied from the Institute for Animal Experimentation, Tohoku University Graduate School of Medicine. Before the experiments, all animals were treated in a similar manner in terms of diet, environmental temperature, and light-dark exposure.

\section{Measurement of ventilation}

Ventilation was measured using the barometric method of plethysmography (Fig. 1) (Bartlett and Tenney 1970), which was basically the same method as described in previous papers (Mizusawa et al. 1994; Ogawa et al. 1995) except for the chamber volume used. An unanesthetized and unrestrained mouse was placed in a $700 \mathrm{ml}$ Plexiglass animal chamber connected to a reference chamber of the same volume through a pressure transducer (model MP-45; Validyne, Northridge, CA, USA). To avoid $\mathrm{CO}_{2}$ gas accumulation in the chamber, the animal chamber had inlet and outlet tubes, which were connected to a gas compressor and a vacuum pump, respectively, allowing constant background flow of humidified room air $(500 \mathrm{ml} / \mathrm{min})$. Calibration of the volume was repeated during each experiment using a gas-tight syringe $(1 \mathrm{ml})$ to inject $0.1 \mathrm{ml}$ into the chamber while the chamber was empty.

Breathing frequency (f) was calculated directly from the ventilation-induced pressure swings. Tidal volume (VT) was obtained as a function of the pressure difference between the two chambers. The equation to calculate VT is described elsewhere (Drorgaugh and Fenn 1955; Bartlett and Tenney 1970). The minute ventilation ( $\dot{V} E)$ was calculated from $\mathrm{f} \times \mathrm{VT}$. VT and $\dot{\mathrm{V} E}$ were normalized with body weight $(\mathrm{g})$.

The $\mathrm{O}_{2}$ fraction concentration $\left(\mathrm{FO}_{2}\right)$ and the $\mathrm{CO}_{2}$ 


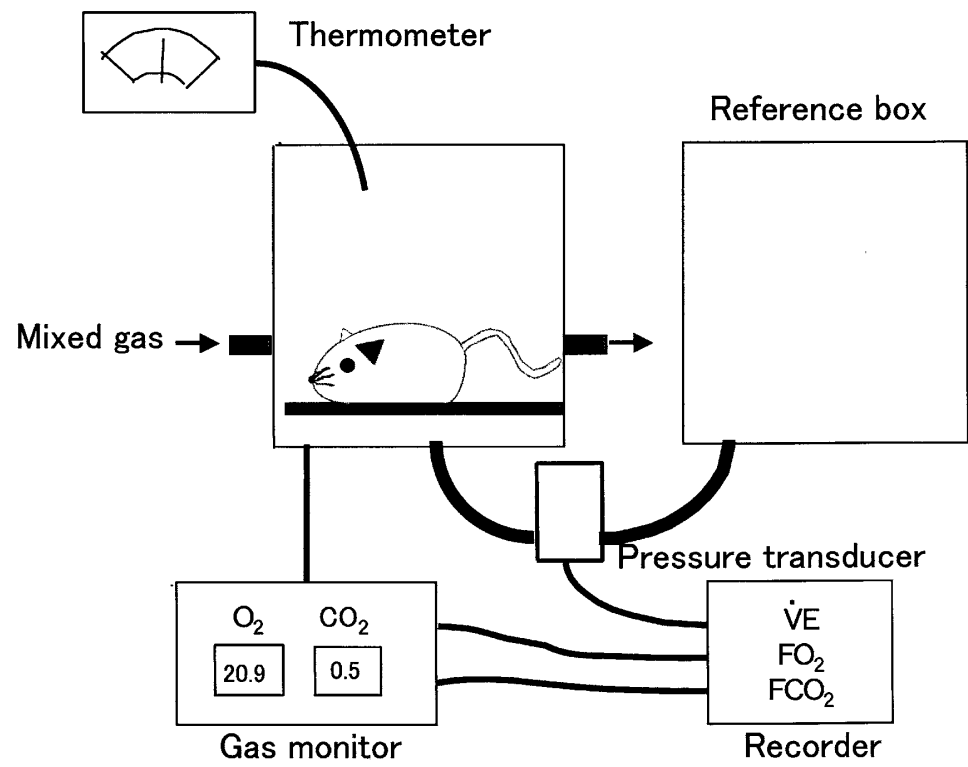

Fig. 1. Schematic diagram of the experimental setup. Each unanesthetized mouse was allowed to acclimate in the chamber at least 30 min before the measurement. $\dot{V E}$, minute ventilation; $\mathrm{FO}_{2}, \mathrm{O}_{2}$ fraction concentration; $\mathrm{FCO}_{2}, \mathrm{CO}_{2}$ fraction concentration.

fraction concentration $\left(\mathrm{FCO}_{2}\right)$ in the chamber were continuously measured with the use of a gas analyzer (model no. $1 \mathrm{H} 21 \mathrm{~A}$; NEC Sanei, Tokyo). $\mathrm{FO}_{2}, \mathrm{FCO}_{2}$ and pressure changes in the animal chamber were recorded on a strip chart recorder (Rectigraph-8S, NEC Sanei).

\section{Acute hypoxic and hypercapnic ventilatory responses}

Freely moving animals were placed in the plethysmograph (CHEST M.I., Inc., Tokyo) breathing room air and given sufficient time of at least $30 \mathrm{~min}$ to acclimate to the surroundings. After stabilization while breathing room air, control ventilation was measured for $15 \mathrm{~min}$. For the ventilatory response to acute hypoxia, $\mathrm{N}_{2}$ gas was mixed with background room air to maintain the chamber $\mathrm{FO}_{2}$ at $10 \%$ and the $\mathrm{FCO}_{2}<0.6 \%$. The hypoxic ventilatory response was obtained under a poikilocapnic condition. For the ventilatory responses to hypercapnia, the $\mathrm{FCO}_{2}$ in the chamber was adjusted to $10 \% \mathrm{CO}_{2}$ using a gas mixture of $40 \% \mathrm{CO}_{2} \sim 60 \% \mathrm{O}_{2}$ in $\mathrm{N}_{2}$ gas. The targeted fraction concentration of $\mathrm{O}_{2}$ or $\mathrm{CO}_{2}$ was obtained within $20 \mathrm{sec}$, and maintained for $3 \mathrm{~min}$. The ventilatory responses to hypoxia were measured for $15 \sim 20 \mathrm{sec}$ at the peak response during $3 \mathrm{~min}$ and those to hypercapnia were measured for the last $15 \sim 20 \mathrm{sec}$ during $3 \mathrm{~min}$ (Mizusawa et al. 1994; Ogawa et al. 1995; Tabata et al. 2001; Adachi et al. 2004), with an interval of at least 30 min and in random order.
The mean values from the two trials were accepted as individual data. The response of each respiratory variable was assessed as the value during hypoxia or hypercapnia minus the corresponding basal value during room air breathing (Mizusawa et al. 1994; Adachi et al. 2004).

\section{Sustained severe hypoxic ventilatory response}

Mice of two strains (AKR/N; $n=13$, and SWR/J; $n=19$ ) were selected for the following reasons. Among the nine strains examined, AKR/N mice had the greatest hypoxic ventilatory response and SWR/J mice had the lowest hypoxic response. After control measurement of the ventilation, the animals were exposed to $6 \% \mathrm{O}_{2}$ in $\mathrm{N}_{2}$ gas, which was adjusted by $\mathrm{N}_{2}$ gas within $20 \mathrm{sec}$. The animals breathed the gas of this targeted fraction of $\mathrm{O}_{2}$ until they exhibited respiratory disturbances such as apnea of $5 \mathrm{sec}$ interval. After the loading of hypoxic gas, the animals breathed room air. We defined the "appearance time of apnea" as the time from the start point of breathing $6 \% \mathrm{O}_{2}$ to the point of occurrence of apnea lasting more than $5 \mathrm{sec}$. We compared the appearance time of apnea between the two strains.

These experiments were approved by the animal experiment review committee of Tohoku University School of Medicine.

All experimental procedures were carried out between a.m. 9:00 and p.m. 6:00 in a quiet and light 
room at an ambient temperature of $25^{\circ} \mathrm{C}$.

Data were presented as means \pm S.E. All data concerning the nine strains were analyzed by one-way analysis of variance (ANOVA), and the differences among strains were compared by post hoc Scheffe's test.
Comparison of the appearance time of apnea between the two strains was by unpaired Student's $t$-test. Differences between the mean values were considered significant when $p<0.05$.

TABLE 1. Respiratory variables during room air breathing, and hypoxic and hypercapnic ventilatory responses of inbred murine strains.

\begin{tabular}{|c|c|c|c|c|c|c|}
\hline Strain & $n$ & Body weight, $g$ & Breathing gas & $\dot{\mathrm{VE}}, \mathrm{ml} / \mathrm{min} / \mathrm{g}$ & $\mathrm{f}, / \mathrm{min}$ & $\mathrm{VT}, \mu \mathrm{l} / \mathrm{g}$ \\
\hline \multirow{3}{*}{$\mathrm{AKR} / \mathrm{N}$} & \multirow{3}{*}{13} & \multirow{3}{*}{$24.8 \pm 0.4$} & room air & $2.75 \pm 0.10$ & $228.3 \pm 7.5$ & $12.1 \pm 0.3$ \\
\hline & & & $10 \% \mathrm{O}_{2}$ & $5.35 \pm 0.13^{*}$ & $312.1 \pm 6.4^{*}$ & $17.2 \pm 0.4^{*}$ \\
\hline & & & $10 \% \mathrm{CO}_{2}$ & $8.40 \pm 0.27^{*}$ & $342.4 \pm 4.1^{*}$ & $24.6 \pm 0.8$ \\
\hline \multirow{3}{*}{$\mathrm{DBA} / 2$} & \multirow{3}{*}{13} & \multirow{3}{*}{$24.5 \pm 0.3 \dagger$} & room air & $2.59 \pm 0.16 \dagger$ & $221.1 \pm 12.1$ & $11.8 \pm 0.4$ \\
\hline & & & $10 \% \mathrm{O}_{2}$ & $4.78 \pm 0.21^{*}$ & $306.7 \pm 6.7^{*}$ & $15.5 \pm 0.5$ \\
\hline & & & $10 \% \mathrm{CO}_{2}$ & $7.46 \pm 0.49$ & $331.3 \pm 10.0$ & $22.2 \pm 0.9 \dagger$ \\
\hline \multirow{3}{*}{$\mathrm{BALB} / \mathrm{c}$} & \multirow{3}{*}{8} & \multirow{3}{*}{$24.4 \pm 0.4 \dagger$} & room air & $2.96 \pm 0.11$ & $233.3 \pm 10.4$ & $12.8 \pm 0.6$ \\
\hline & & & $10 \% \mathrm{O}_{2}$ & $4.88 \pm 0.25^{*}$ & $321.8 \pm 5.6^{*}$ & $15.1 \pm 0.6$ \\
\hline & & & $10 \% \mathrm{CO}_{2}$ & $8.50 \pm 0.42$ & $330.9 \pm 12.3$ & $25.7 \pm 0.8$ \\
\hline \multirow{3}{*}{$\mathrm{C} 3 \mathrm{H} / \mathrm{He}$} & \multirow{3}{*}{11} & \multirow{3}{*}{$24.6 \pm 0.4 \dagger$} & room air & $2.55 \pm 0.07 \dagger$ & $217.0 \pm 8.0 \dagger$ & $11.9 \pm 0.5$ \\
\hline & & & $10 \% \mathrm{O}_{2}$ & $4.33 \pm 0.15$ & $262.9 \pm 6.3 \dagger$ & $16.5 \pm 0.4$ \\
\hline & & & $10 \% \mathrm{CO}_{2}$ & $6.83 \pm 0.21$ & $309.6 \pm 4.4$ & $22.0 \pm 0.5 \dagger$ \\
\hline \multirow{3}{*}{$\mathrm{A} / \mathrm{J}$} & \multirow{3}{*}{12} & \multirow{3}{*}{$24.3 \pm 0.3 \dagger$} & room air & $3.30 \pm 0.16^{*}$ & $236.8 \pm 10.0$ & $14.0 \pm 0.6^{*}$ \\
\hline & & & $10 \% \mathrm{O}_{2}$ & $5.00 \pm 0.26^{*}$ & $301.7 \pm 7.6^{*}$ & $16.5 \pm 0.7$ \\
\hline & & & $10 \% \mathrm{CO}_{2}$ & $8.29 \pm 0.48$ & $289.7 \pm 6.1 \dagger$ & $28.4 \pm 1.3^{*}$ \\
\hline \multirow{3}{*}{ C57BL/6 } & \multirow{3}{*}{10} & \multirow{3}{*}{$23.1 \pm 0.4 \dagger$} & room air & $3.13 \pm 0.20^{*}$ & $269.4 \pm 10.3$ & $11.7 \pm 0.8$ \\
\hline & & & $10 \% \mathrm{O}_{2}$ & $4.72 \pm 0.28$ & $287.8 \pm 13.6$ & $16.4 \pm 0.6$ \\
\hline & & & $10 \% \mathrm{CO}_{2}$ & $7.80 \pm 0.43$ & $342.1 \pm 9.6^{*}$ & $22.7 \pm 1.0 \dagger$ \\
\hline \multirow{3}{*}{$129 \mathrm{sv}$} & \multirow{3}{*}{8} & \multirow{3}{*}{$27.3 \pm 1.1^{*}$} & room air & $2.32 \pm 0.13 \dagger$ & $218.2 \pm 9.0$ & $10.6 \pm 0.3 \dagger$ \\
\hline & & & $10 \% \mathrm{O}_{2}$ & $3.84 \pm 0.14 \dagger$ & $273.6 \pm 6.3$ & $14.0 \pm 0.4 \dagger$ \\
\hline & & & $10 \% \mathrm{CO}_{2}$ & $7.27 \pm 0.23$ & $332.0 \pm 14.9$ & $22.2 \pm 1.2 \dagger$ \\
\hline \multirow{3}{*}{ NZW } & \multirow{3}{*}{8} & \multirow{3}{*}{$25.2 \pm 0.4$} & room air & $2.15 \pm 0.07 \dagger$ & $215.7 \pm 7.5$ & $10.0 \pm 0.3 \dagger$ \\
\hline & & & $10 \% \mathrm{O}_{2}$ & $3.54 \pm 0.17 \dagger$ & $259.7 \pm 7.4 \dagger$ & $13.6 \pm 0.3 \dagger$ \\
\hline & & & $10 \% \mathrm{CO}_{2}$ & $6.10 \pm 0.27 \dagger$ & $291.1 \pm 4.5 \dagger$ & $21.0 \pm 0.8 \dagger$ \\
\hline \multirow{3}{*}{$\mathrm{SWR} / \mathrm{J}$} & \multirow{3}{*}{14} & \multirow{3}{*}{$23.1 \pm 0.3 \dagger$} & room air & $3.30 \pm 0.09^{*}$ & $270.2 \pm 9.8^{*}$ & $12.4 \pm 0.6$ \\
\hline & & & $10 \% \mathrm{O}_{2}$ & $4.29 \pm 0.09 \dagger$ & $261.2 \pm 6.2 \dagger$ & $16.5 \pm 0.4$ \\
\hline & & & $10 \% \mathrm{CO}_{2}$ & $8.72 \pm 0.27^{*}$ & $344.4 \pm 6.7^{*}$ & $25.3 \pm 0.5$ \\
\hline
\end{tabular}

Values are means \pm S.E. $\dot{V}$ E, minute ventilation; $f$, breathing frequency; VT, tidal volume. Significant interstrain variability $(p<0.05)$ was determined for each dependent variable. Significant $(p<0.05)$ mean differences among strains are indicated by ${ }^{*}$ or $\dagger$, representing strains not different from one another but relatively high or low responses, respectively, within a strain distribution. 


\section{RESUlts}

Room air breathing. The body weight and respiratory variables during air breathing are summarized in Table 1. There were significant differ-
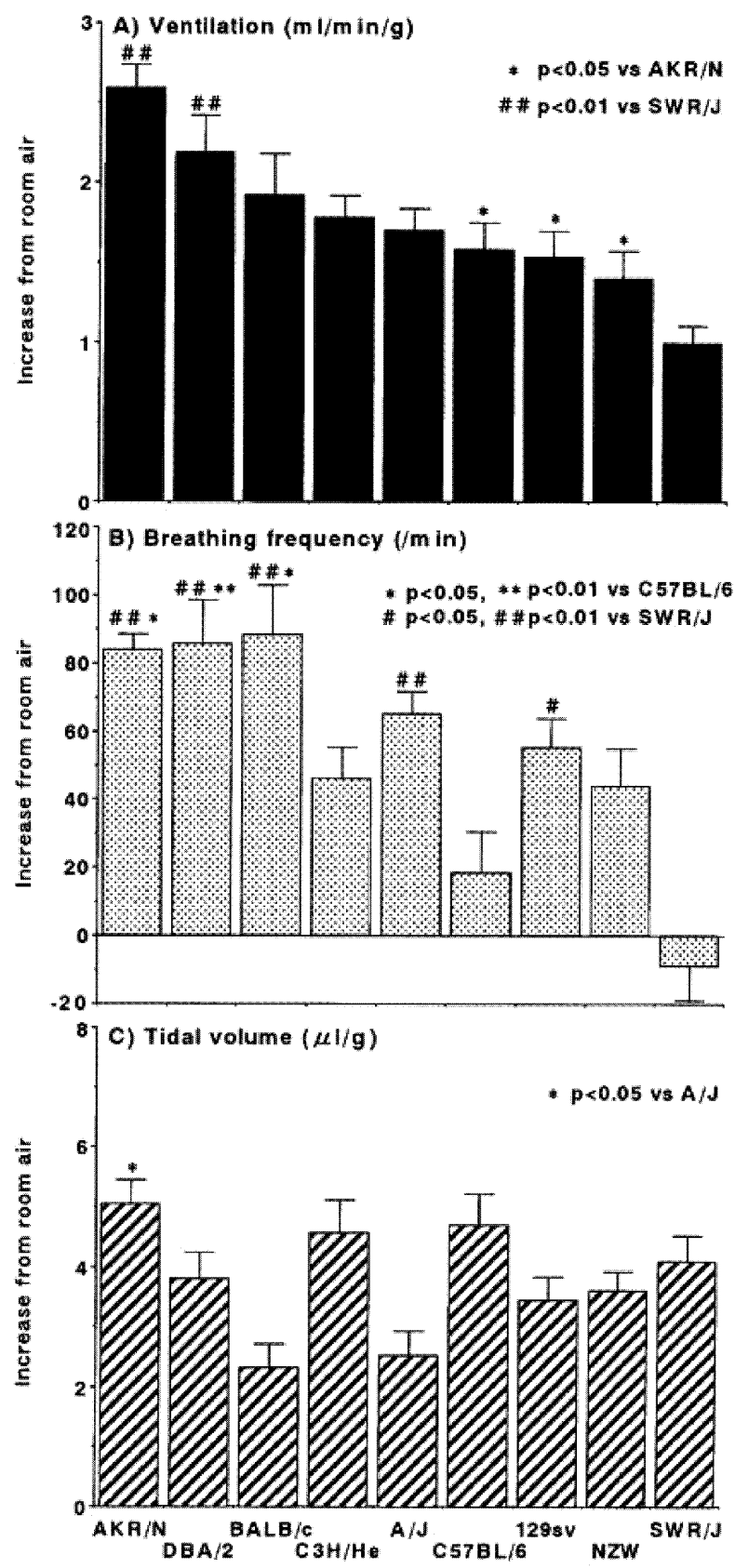

Fig. 2. Hypoxic ventilatory responses of the nine murine strains. Significant differences were observed among the strains. Note that the hypoxic response of $\mathrm{AKR} / \mathrm{N}$ is the highest and that of SWR/J is the lowest among the nine strains. ences in VE, VT or breathing frequency among the nine strains. However, there were no significant differences in these three parameters between $\mathrm{AKR} / \mathrm{N}$ and SWR/J mice examined in the study of the severe hypoxic ventilatory response.

Acute hypoxic and hypercapnic ventilatory responses. Fig. 2 shows the hypoxic ventilatory
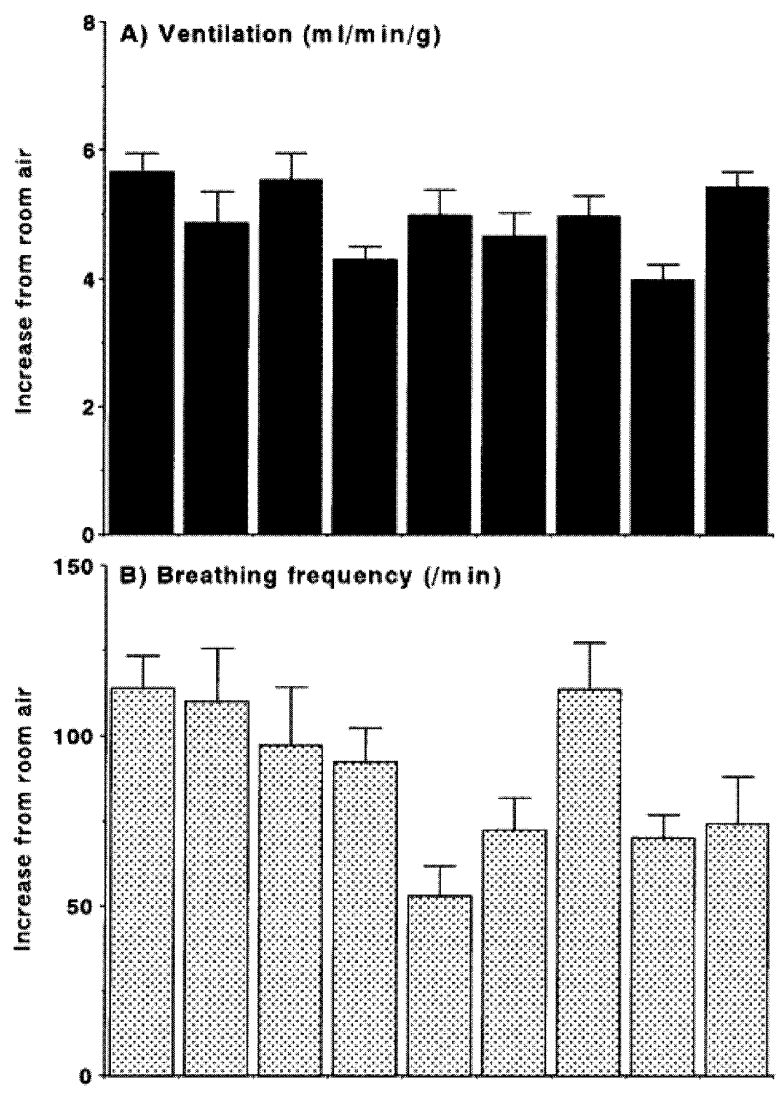

$20]$ C) Tidal volume $(\mu l / g)$

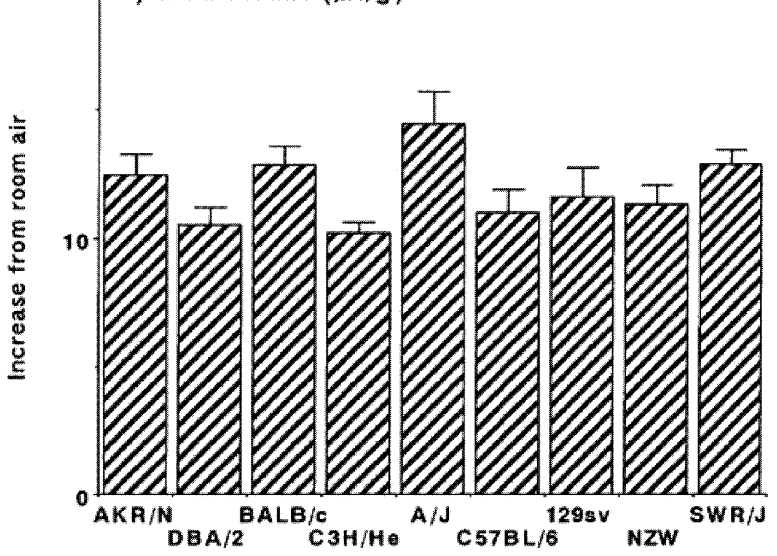

Fig. 3. Hypercanic ventilatory responses of the nine murine strains. No significant differences were observed among the strains. 


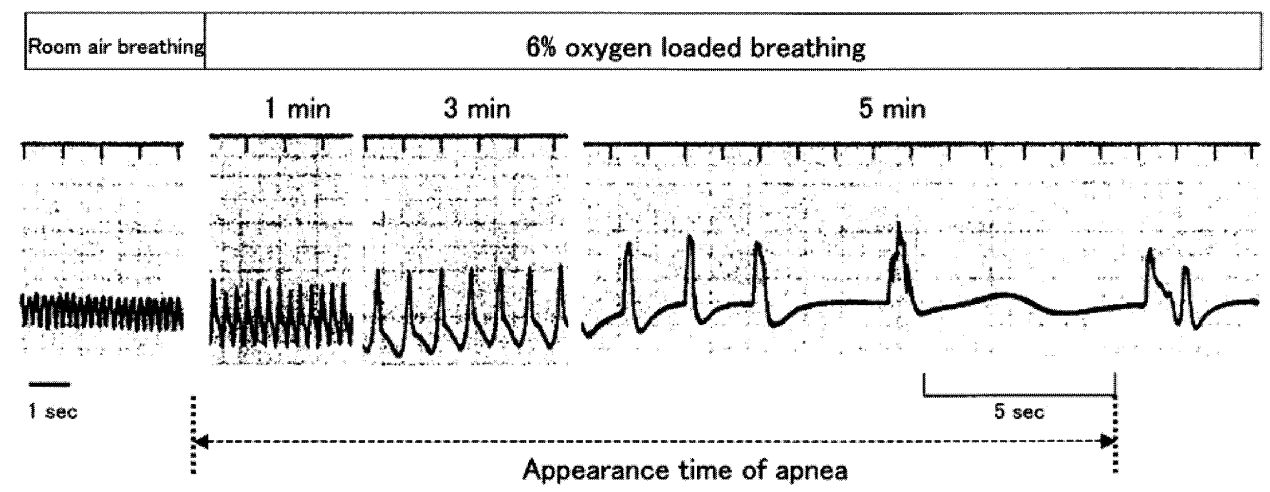

Fig. 4. Representative ventilatory response to severe hypoxic stress. Apnea over $5 \mathrm{sec}$ was observed at 5 min after the onset of exposure of $6 \% \mathrm{O}_{2}$ in $\mathrm{N}_{2}$ gas. This time was defined as "appearance time of apnea."

response of the 9 inbred mouse strains. The strains were placed in order of magnitude of the ventilatory response from highest to lowest. There was great diversity among the strains. AKR/N showed the highest hypoxic ventilatory response with increases in both $f$ and VT. SWR/J showed the lowest hypoxic ventilatory response with an increase in VT. Interestingly, SWR/J did not show a significant change in $\mathrm{f}$ during acute hypoxic gas exposure. The difference of ventilation between these two strains was not due to the difference of tidal volume, but to the difference of respiratory frequency.

Fig. 3 shows the hypercapnic ventilatory response of the 9 inbred mouse strains. The displayed order is similar to the order in Fig. 2. There was no significant difference in the ventilatory response to hypercapnia among the strains.

Sustained severe hypoxic ventilatory response. Fig. 4 shows a representative trace of the breathing curve, which shows resting breathing and breathing at 1,3 and 5 min after hypoxic loading. After 1 minute, the tidal volume increased. After $3 \mathrm{~min}$, the respiratory frequency decreased and the tidal volume increased. After 5 min, the interval between breathing cycles was prolonged progressively, and apnea of more than $5 \mathrm{sec}$ appeared. We obtained "appearance time of apnea" defined as the time from the hypoxic loading to the onset of apnea. In this case, appearance time of apnea was $5 \mathrm{~min}$.

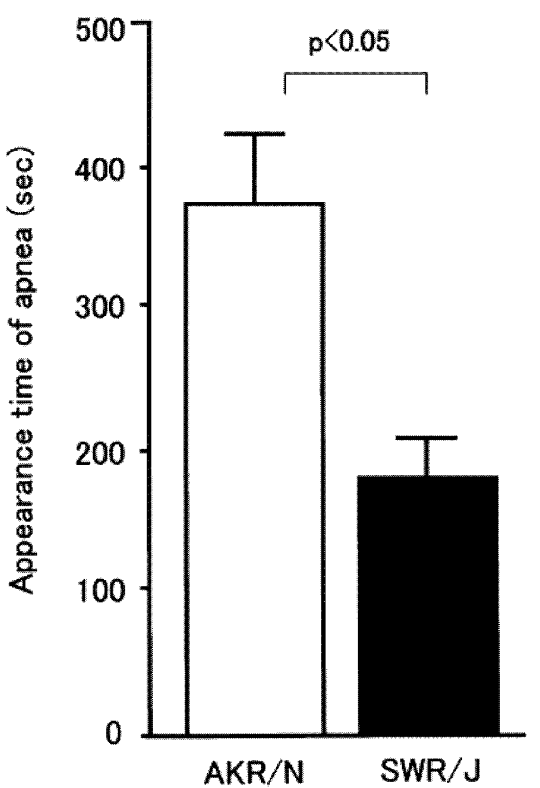

Fig. 5. Appearance time of apnea of $A K R / N$ and SWR/J strains. Appearance time of SWR/J was significantly shorter than that of AKR/N.

Fig. 5 shows the appearance times of apnea of the AKR/N and SWR/J strains. The appearance time of SWR/J mice was shorter than that of AKR/N mice. This suggests that SWR/J mice with a lower hypoxic ventilatory response are prone to apnea within a shorter period under hypoxia. We could resuscitate the mice after the first apnea by exposing them to air after the hypoxic loading. 


\section{Discussion}

We studied the acute hypoxic and hypercapnic ventilatory responses of 9 inbred mouse strains and the effects of sustained severe hypoxic loading on the breathing pattern of two strains with the highest or lowest hypoxic ventilatory responses. We found great diversity among the strains in terms of the respiratory variables during air breathing and in the hypoxic ventilatory response. Such diversity among the strains corresponded with the results of previous papers, which showed variability in lung function (Reinhard et al. 2002) and airway responsiveness (De Sanctis and Drazen 1997) among inbred strains. The hypoxic ventilatory response in the AKR/N strain was the highest, and the hypoxic ventilatory response in the SWR/J strain was the lowest among the 9 strains examined in the present study. The hypercapnic ventilatory responses did not differ among the 9 strains. Furthermore, we found that hypoxic-induced apnea occurred after a shorter period in $\mathrm{SWR} / \mathrm{J}$ mice than in AKR/N strain. These findings suggest that the hypoxic ventilatory response, but not the hypercapnic ventilatory response was determined by genetic factors, and that animals with a blunted hypoxic ventilatory response would have a weaker compensation in response to hypoxia.

The targeted fractional concentration of the hypoxic response was $10 \% \mathrm{O}_{2}$ in $\mathrm{N}_{2}$. This hypoxic level is generally accepted in studies of small animals. On the other hand, the target $\mathrm{CO}_{2}$ concentration, $10 \% \mathrm{CO}_{2}$ in over $40 \% \mathrm{O}_{2}$, might be higher. In additional experiments, we studied the graded hypercapnic ventilatory response using $5 \% \mathrm{CO}_{2}, 10 \% \mathrm{CO}_{2}$ and $12 \% \mathrm{CO}_{2}$ in over $40 \% \mathrm{O}_{2}$ in an additional $6 \mathrm{AKR} / \mathrm{N}$ mice and $6 \mathrm{SWR} / \mathrm{J}$ mice. We found a linear response up to $12 \% \mathrm{CO}_{2}$ (data not shown). Therefore, the $10 \% \mathrm{CO}_{2}$ applied in this study seemed to be acceptable.

In the present study, we could not measure the arterial oxygen tension $\left(\mathrm{PaO}_{2}\right)$ or arterial $\mathrm{CO}_{2}$ tension from the arterial blood. The reason for this is that this series of experiments was performed under a freely moving and unanaesthetized condition and blood sampling would have been technically difficult. Instead, we assessed the chamber $\mathrm{FO}_{2}$ or $\mathrm{FCO}_{2}$ instead of $\mathrm{PaO}_{2}$ or $\mathrm{PaCO}_{2}$.

Furthermore, as we did not monitor the cardiovascular parameters, it was difficult to determine whether cardiac arrest occurred before the occurrence of apnea in the study of the sustained hypoxic ventilatory response. However, as the mice recovered from apnea after air breathing or the heart beat was recognized by touching, the apneic episodes during severe hypoxic loading could be expected to have occurred independently of near arrest.

Tankersley et al. (1994) studied the interstrain variance of the ventilatory response to normal air, hypoxia and hypercapnia among eight inbred strains of mice. They found significant inter-strain differences in ventilation during air breathing and in the ventilatory response to two chemical loadings, and these inter-strain differences might have been influenced by genetic determinants. The present study seemed to support partly the study by Tankersley et al. (1994). Several mouse strains of the present study were the same as those used in Tankersley's study, such as DBA/2, BALB/c, C3H/He, C57BL/6 and A/J. The order of the increase in the hypoxic ventilatory response in these strains was compatible with their study, except for the case of C57BL/6. The reasons for some of the differences between the two reports may be as follows. One possibility may be the different time domains in the hypoxic response, which are thought to reflect different physiological systems (Huey and Powell 2000). Another possibility may be differences in the phenotyping strategy in terms of the length of exposure or degree of loaded gas. Furthermore, there were differences in the time of day that the studies were performed, the degree to which the mechanical aspects of control were measured and the mouse strains that were used.

Han et al. (2001) reported the ventilatory behavior after $8 \%$ oxygen in C57BL/6 and A/J mice. They did not find a difference in the $\dot{V} E$ response between the two strains. However, they found greater increase in $\mathrm{f}$ and less increase in VT in the $\mathrm{A} / \mathrm{J}$ strain compared to the $\mathrm{C} 57 \mathrm{BL} / 6$ strain. 
The ventilatory behavior after hypoxic exposure in the $\mathrm{C} 57 \mathrm{BL} / 6$ and $\mathrm{A} / \mathrm{J}$ mice used in the present study was consistent with Han et al. (2001). Furthermore, our study may support clinical studies by Kawakami et al. (1982, 1984), who reported that genetic factors might influence the ventilatory response to hypoxia but not that to hypercapnia, as judged from studies concerning hypoxic and hypercapnic ventilatory responses in twins.

The underlying mechanisms of the hypoxic ventilatory response have been elucidated in terms of the neurotransmitters or neuromodulators in the central nervous system. The nitric oxide (NO) in the nucleus tractus solitarii plays an important role on the acute phase during hypoxic stress, and this works as a retrograde messenger in an excitatory transmitter, L-glutamate, releasing a positive feedback system that contributes to the augmentation of ventilation during hypoxia (Mizusawa et al. 1994; Ogawa et al. 1995). The facilitation of the L-glutamate release system by NO might contribute to the prevention of abrupt changes in ventilation.

Recently, we have reported that mice lacking heme oxygenase-2 (HO-2) show attenuated ventilatory responses to hypoxia with normal responses to hypercapnia (Adachi et al. 2004), suggesting that HO-2 might play a role as an oxygen sensor or a heme-containing regulator (Shibahara 2003). Incidentally, the degree of the blunted hypoxic response seen in $\mathrm{SWR} / \mathrm{J}$ mice is similar to that seen in HO-2 (-/-) mice. Thus, SWR/J mice may provide a suitable alternative to $\mathrm{HO}-2$ (-/-) mice. Furthermore, the SWR/J mouse strain characteristically carries the Cys variation in the juxtamembrane domain of the c-Met receptor tyrosine kinase, proven to functionally modulate tumorigenesis (Zaffaroni et al. 2005). In this context, the SWR/J mouse has been known as a strain highly susceptible to lung tumorigenesis (Rabstein et al. 1973). It is therefore tempting to speculate that c-Met and its ligand, hepatocyte growth factor, might be involved in oxygen sensing.

On the other hand, in the decline phase of ventilation during sustained hypoxic loading, $\gamma$-aminobutyric acid (GABA), which is an inhibi- tory transmitter, in the NTS had an important role in the hypoxic ventilatory decline after sustained hypoxic loading (Tabata et al. 2001). Whether a GABAergic mechanism affects the onset of apnea under severe hypoxic stress is still unknown.

It was reported that the patients who had a history of near-miss death from sudden infant death syndrome (Hunt et al. 1981) and asthma attacks (Kikuchi et al. 1994), or who experienced high altitude pulmonary edema had blunted hypoxic chemosensitivity. From these clinical studies, we speculated that persons with a blunted hypoxic ventilatory response may have a weak defense response to hypoxic episodes and be susceptible to fatal respiratory disturbances. The present study in which animals with blunted hypoxic chemosensitivity had respiratory depression as indicated by hypoxic induced apnea, may suggest that the level of chemosensitivity plays a role in occurrence of apnea in sleep apnea syndrome.

Obstructive sleep apnea (OSA), which causes hypoxemia by repetitive apneas during sleep mainly due to upper airway obstruction (Miki et al. 1988; Hida et al. 1994; Taguchi et al. 1997; Hida 1998), results in rapidly progressive hypercapnia and hypoxia, which could initiate reopening of the upper airway and determine the postapneic ventilation together with nonchemical factors (Satoh et al. 1991; Kimoff et al. 1994). Satoh et al. (1991) reported that the slopes of the regression line obtained from the relationships between arterial oxygen saturation $\left(\mathrm{SaO}_{2}, \%\right)$ induced by apnea and the postapneic ventilation during both rapid eye movement (REM) and nonREM sleep correlated well with the hypoxic ventilatory response (HVR) during wakefulness in OSA patients. These results suggest that the slopes might partly reflect hypoxic responsiveness during sleep in OSA patients. If so, we could compare HVR during sleep with that while awake in OSA. We found that the awake HVR was higher than that during both sleep stages, and that the HVR during REM sleep is less than that of non-REM sleep. Thus, the ventilatory response to hypoxic stress is lowest during REM sleep among the three states. Generally, respiratory distur- 
bances are prone to occur during REM sleep more than during non-REM sleep. A lower hypoxic ventilatory response during REM sleep may have a relationship with the easier occurrence of apnea (Hida 1998).

During sustained hypoxia, ventilation is known to show a biphasic response, which is comprised of an initial stimulatory phase mediated by peripheral chemoreceptors and then a depressive phase caused by central and/or peripheral mechanisms in animals and in humans (Easton et al. 1986; Neubauer et al. 1987). The response to sustained hypoxia has been examined under moderate hypoxic conditions such as $\mathrm{FiO}_{2} 10 \%$. In the present study we examined the time until the onset of apnea under severe hypoxic loading of $6 \% \mathrm{O}_{2}$ in $\mathrm{N}_{2}$ gas. This method was basically similar to that used in a previous study by Scremin et al. (1980), except that they obtained the time from the start of exposure of the same level of hypoxic gas until the last gasp as the survival time. Severe hypoxia could cause apnea, that is, hypoxic-induced apnea (Guntheroth and Kawabori 1975; Fewell et al. 2005). Although the mechanism of hypoxic-induced apnea is not known, we speculate that central hypoxic depression may result from a positive feedback mechanism (Tabata et al. 2001) inducing apnea, or that hyperventilation during hypoxic loading may induce apnea in the same manner as post-hyperventilation apnea induced by hypocapnia below the apneic threshold (Meah and Gardner 1994).

The main findings of the present study were that genetic factors influenced the ventilatory responses to both the brief and sustained hypoxic loading but not the hypercapnic ventilatory response, and that a lower hypoxic ventilatory response could lead to hypoxic-induced apnea. As the present study was performed under prolonged hypoxic exposure in awake mice, our results may have limited value in explaining the mechanisms of intermittent apnea during sleep in sleep apnea syndrome. However, these findings may be helpful to explain fatal respiratory disturbances observed clinically under hypoxic conditions of various diseases such as chronic obstructive pulmonary disease (Ichinose 2003; Takemura et al. 2005) and sleep apnea syndrome (Miki et al. 1988; Hida et al. 1994; Taguchi et al. 1997; Hida 1998).

\section{Acknowledgments}

The authors would like to thank Mr. B. Bell for reading the manuscript. This effort was supported in part by Grants-in-Aid for Scientific Research (No. 16590731 and No. 16390071) from the Ministry of Education, Science, Sports and Culture of Japan.

\section{References}

Adachi, T., Ishikawa, K., Hida, W., Matsumoto, H., Masuda, T., Date, F., Ogawa, K., Takeda, K., Furuyama, K., Zhang, Y., Kitanura, T., Ogawa, H., Maruyama, Y. \& Shibahara, S. (2004) Hypoxemia and blunted hypoxic vetilatory responses in mice lacking heme oxygenase-2. Biochem. Biophys. Res. Commun., 320, 514-522.

Bartlett, D., Jr. \& Tenny, S.M. (1970) Control of breathing in experimental anemia. Respir. Physiol., 10, 384-395.

De Sanctis, G.T. \& Drazen, J.M. (1997) Genetics of native airway responsiveness in mice. Am. J. respir. Crit. Care Med., 156, 82-88.

Drorbaugh, J.E. \& Fenn, W.O. (1955) A barometric method for measuring ventilation in newborn infants. Pediatrics, 16, 81-86.

Easton, P.A., Slykerman, L.J. \& Anthonisen, N.R. (1986) Ventilatory response to sustained hypoxia in normal adults. J. Appl. Physiol., 61, 906-911.

Fewell, J.E., Ng, V.K.Y. \& Zhang, C. (2005) Prior exposure to hypoxic-induced apnea impairs protective responses of newborn rats in an exposure-dependent fashion: influence of normoxic recovery time. J. Appl. Physiol., 99, $1607-1612$.

Guntheroth, W.G. \& Kawabori, I. (1975) Hypoxic apnea and gasping. J. Clin. Invest., 56, 1371-1377.

Hackett, P.H., Roach, R.C., Schoene, R.B., Harrison, G.L. \& Mills, W.J., Jr. (1988) Abnormal control of ventilation in high-altitude pulmonary edema. J. Appl. Physiol., 64, 1268-1272.

Han, F., Subramanian, S., Dick, T.E., Dreshaj, I.A. \& Strohl, K.P. (2001) Ventilatory behavior after hypoxia in C57BL/6 J and A/J mice. J. Appl. Physiol., 91, 1962-1970.

Hida, W. (1998) New strategies of screening and treatment for sleep apnea syndrome. Tohoku. J. Exp. Med., 186, 225-241.

Hida, W., Okabe, S., Miki, H., Kikuchi, Y., Taguchi, O., Takishima, T. \& Shirato, K. (1994) Effects of submental stimulation for several consecutive nights in patients with obstructive sleep apnoea. Thorax, 49, 4446-452.

Huey, K.A. \& Powell, F.L. (2000) Time-dependent changes in dopamine D2-receptor mRNA in the arterial chemoreflex pathway with chronic hypoxia. Molecular Brain Res., 75, 264-270.

Hunt, C.E., McCulloch, K. \& Brouillette, R.T. (1981) Diminished hypoxic ventilatory responses in near-miss sudden infant death syndrome. J. Appl. Physiol., 50, 1313-1317.

Ichinose, M. (2003) Inflammatory mechanisms in bronchial asthma and COPD. Tohoku J. Exp. Med., 200, 1-6.

Kawakami, Y., Yoshikawa, T., Shida, A., Asanuma, Y. \& Murao, M. (1982) Control of breathing in young twins. J. Appl. 
Physiol., 52, 537-542.

Kawakami, Y., Yamamoto, H., Yoshikawa, T. \& Shida, A. (1984) Chemical and behavioral control of breathing in adult twins. Am. Rev. Respir. Dis., 129, 703-707.

Kikuchi, Y., Okabe, S., Tamura, G., Hida, W., Homma, M., Shirato, K. \& Takishima, T. (1994) Chemosensitivity and perception of dyspnea in patients with a history of nearfatal asthma. N. Engl. J. Med., 330, 1329-1334.

Kimoff, R., Cheong, T.H., Olha, A., Charbonneau, M., Levy, R.D., Cosio, M.G. \& Gottfried, S.B. (1994) Mechanisms of apnea termination in obstructive sleep apnea. Role of chemoreceptor and mechanoreceptor stimuli. Am. J. Respir. Crit. Care Med., 149, 707-714.

Meah, M.S. \& Gardner, W.N. (1994) Post-hyperventilation apnoea in conscious humans. J. Physiol. (London), 477, 527-538.

Miki, H., Hida, W., Inoue, H. \& Takishima, T. (1988) A new treatment for obstructive sleep apnea syndrome by electrical stimulation of submental region. Tohoku J. Exp. Med., 154, 91-92.

Mizusawa, A., Ogawa, H., Kikuchi, Y., Hida, W., Kurosawa, H., Okabe, S., Takishima, T. \& Shirato, K. (1994) In vivo release of glutamate in nucleus tractus solitarii of the rat during hypoxia. J. Physiol. (London), 478, 55-65.

Neubauer, J.A., Posner, M.A., Santiago, T.V. \& Edelman, N.H. (1987) Naloxone reduces ventilatory depression of brain hypoxia. J. Appl. Physiol., 63, 699-706.

Ogawa, H., Mizusawa, A., Kikuchi, Y., Hida, W., Miki, H. \& Shirato, K. (1995) Nitric oxide as a retragrade messenger in the nucleus tractus solitarii of rats during hypoxia. $J$. Physiol. (London), 486, 495-504.

Rabstein, L.S., Peters, R.L. \& Spahn, G.J. (1973) Spontaneous tumors and pathologic lesions in SWR-J mice. J. Natl. Cancer Inst., 50, 751-758.

Reinhard, C., Eder, G., Fuchs, H., Ziesenis, A., Heyder, J. \& Schulz, H. (2002) Inbred strain variation in lung function.
Mammalian Genome, 13, 429-437.

Satoh, M., Hida, W., Chonan, T., Miki, H., Iwase, N., Taguchi, O., Okabe, S., Kikuchi, Y. \& Takishima, T. (1991) Role of hypoxic drive in regulation of postapneic ventilation during sleep in patients with obstructive sleep apnea. Am. Rev. Respir. Dis., 143, 481-485.

Scremin, A.M.E., Scremin, O.U. \& Brechner, T. (1980) Survival under hypoxia. Age dependence and effect of cholinergic drugs. Stroke, 11, 548-552.

Shibahara, S. (2003) The heme oxygenase dilemma in cellular homeostasis: new insights for the feedback regulation of heme catabolism. Tohoku J. Exp Med., 200, 167-186.

Tabata, M., Kurosawa, H., Kikuchi, Y., Hida, W., Ogawa, H., Okabe, S., Tun, Y., Hattori, T. \& Shirato, K. (2001) Role of GABA within the nucleus tractus solitarii in the hypoxic vetilatory decline of awake rats. Am. J. Physiol. Regulatory Integrative Comp. Physiol., 281, R1411-R1419.

Taguchi, O., Hida, W., Okabe, S., Ebihara, S., Ogawa, H., Kikuchi, Y. \& Shirato, K. (1997) Improvement of exercise performance with short-term nasal continuous positive airway pressure in patients with obstructive sleep apnea. Tohoku J. Exp. Med., 183, 45-53.

Takemura, H., Hida, W., Sasaki, T., Sugawara, T. \& Sen, T. (2005) Prevalence of chronic obstructive pulmonary disease in Japanese people on medical check-up. Tohoku J. Exp. Med., 207, 41-50.

Tankersley, C.G., Fitgerald, R.S. \& Kleeberger, S.R. (1994) Differential control of ventilation among inbred strains of mice. Am. J. Physiol., 267, R1371-R1377.

Zaffaroni, D., Spinola, M., Galvan, A., Falvella, F.S., Pazzaglia, S., Saran, A., Mancuso, M.T., Galbiati, F., Pignatiello, C., Cabrera, W., Ibanez, O., Manenti, G. \& Dragani, T.A. (2005) Met proto-oncogene juxtamembrane rare variations in mouse and humans: differential effects of Arg and Cys alleles on mouse lung tumorigenesis. Oncogene, 24, 1084-1090. 